\title{
Weaning Practices among Breastfeeding Mothers Local Communities of Enugu State Nigeria
}

\section{Ezenduka $\mathrm{PO}^{1}, \mathrm{Ndie}^{\mathrm{EC}^{2 *}}$ and Nwankwo $\mathrm{CU}^{1}$}

${ }^{1}$ Department of Nursing Science, Nnamdi Azikiwe University, Faculty of Health Sciences and Technology, Nnewi Campus, Nigeria

${ }^{2}$ Department of Nursing Science, Ebonyi State University Abakaliki, Nigeria

"Corresponding author: Ndie EC, Department of Nursing Science, Ebonyi State University Abakaliki, Nigeria, Tel: 2347066789961; E-mail: chubike05@yahoo.com Received date: August 18, 2017; Accepted date: May 15, 2018; Published date: May 24, 2018

Copyright: (C2018 Ezenduka PO, et al. This is an open-access article distributed under the terms of the Creative Commons Attribution License, which permits unrestricted use, distribution, and reproduction in any medium, provided the original author and source are credited.

\begin{abstract}
Introduction: Weaning is a time during which the mother and her new born baby are expected to adjust to the emotional and nutritional demands of life processes including weaning food required for growth and development. The purpose of this study was to determine the weaning practices of breastfeeding mothers attending Postnatal and Child Welfare services in rural communities of Enugu North Local Government Area of Enugu State-Nigeria.

Methods: A descriptive research design was used. A convenient sample of 221 mothers was used. Interview guide was the instrument used for data collection.

Results: Result revealed that only $5.0 \%$ of mothers had no formal educations. $50.2 \%$ of mothers were civil servants; $12.2 \%$ were students; $24.4 \%$ were traders. Only $11.8 \%$ were full time house wife. Only $40.7 \%$ actually know the real meaning of weaning. Sources of information include: Health workers; parent/sisters in laws; printed materials. All mothers breast fed their infants. Weaning was started as early as less than two months by $4.5 \%$ of mothers, while up to $82.4 \%$ started between $7-9$ months of age.

Discussion: Adult diet were introduced as early as the first two months of life; major sources of information were health workers, parents, husband and significant others. Weaning was started at less than two months of age but majority started from seven months and above. Reasons weaning the infant are varied: mother being pregnant, insufficient breast milk, wish of husband, mother and relations were the main reasons provided for starting weaning infants.

Conclusion: Mothers were health educated on proper meaning of weaning, timing; and suitable local food mixes to use, as well as implications for poor weaning.
\end{abstract}

Keywords: Weaning practice; Breastfeeding; Mothers and local communities

\section{Introduction}

One of the inborn characteristics of mammals is to breast feed their young after delivery using their natural breast milk that is highly required for growth and development especially within the first six months of life. Beyond the six month, the infant requires vitamins, iron and extra energy for growth and sustenance of life through the introduction of weaning food [1].

Weaning is the gradual process of introducing an infant to solid food while still breast feeding till he/she can handle adult food physiologically. It is the process of gradual introduction of solid food to an infant's feeding schedule with the ultimate aim of replacing breast or bottle feeds with adult diet [2]. To support this, adequate and proper infant weaning practices adopted by nursing mothers are very crucial to achieve stipulated growth [3].

Weaning practices are all the activities carries out by nursing mothers during the process of weaning. The practice involves what weaning practice means to the mothers, types of food substances used, as well as food mixes utilized. There is no particular food substance or formula to use. The approach differs from country to country and from one community to another. Same is guided by culture, individual beliefs, custom, attitudes, values, the types of local food substances available, level of education, the stage of development, and technology the particular community has attained.

The type of weaning food the mother gives varies according to the local community. In Nigeria and Enugu State in particular, grains processed inform of gruel, usually referred to as pap (Akamu in Igbo Language or Ogi in Yoruba language) are used. It is obvious that babies experience rapid growth during this stage of development. To support this, proper weaning practices are very crucial. Any deviation from normal weaning diet results in growth retardation and complications ranging growth and others.

Despite the campaign on proper weaning practices and efforts made by World Health Organization (WHO) on weaning practices in Nigeria, especially in the rural communities of Enugu state as evidenced by the researchers. In the health centres, it was observed that children between the ages of 4 and 10 months brought for treatment suffer from high rate of gastroenteritis, diarrhoea, vomiting, severe anaemia, pneumonia, failure to thrive (underweight) obesity among others. This supports the claim [4] that weaning represents a dangerous time for infants. Interview with mothers revealed that 
Page 2 of 5

illness started after the introduction of weaning foods (adult diet) either to complement breast milk or weaning the child off the breast. The method of such food preparation was varied. Many mothers were not aware of the special needs of their infants, how to prepare adequate diet from locally available food substances, food mixes to use and correct methods for weaning. Some with feeding bottle over-dilute the feed to make it last long, while some practiced wrong schedule which resulted in health problems. Some mothers were too poor to provide sufficient and right nutritious food adequate for infant normal growth and development. During home visiting, it was observed that in some families the infant is abruptly introduced into family menu with its attendant health problems as the child may not be able to eat enough adult diet to meet up with the nutritional demands. Some mothers have already started infants with finger foods. In a research carried out by a team of UK specialists noted that most babies can actually reach out for food and eat finger by 6 months but this could lead to nutritional problems for the infants. The period was also noted to be teething period for the infants who have painful gums and will not want to come off breast to cope with the hard spoon [2]. It is the intention of the researchers to find out the actual weaning practice adopted by nursing mothers' choices and decisions in those aspects involved in weaning with a view to preventing infections, infant deaths and promoting the health of infants.

The aim of the study is to identify the weaning practices adopted by breast feeding mothers attending maternal and child welfare clinics (services) in rural communities in Enugu East Local Government of Enugu State.

\section{Methods}

The study adopted a descriptive survey research design approach and a non-random sampling technique. Enugu East is made up of six autonomous communities and four health centres which were all used for the study. These health centres take care of maternal and child health services. All mothers who came for post-natal and immunization of their infants were used for the study. Purposive sampling method was used to select 221 breastfeeding mothers. The population was made up of 221 breastfeeding mothers with infants one day-10 months old that attended post-natal and child welfare services provided at the health centres within the communities used for the study. They were all used for the study. Mothers were chosen irrespective of their age, marital status, parity, level of education and occupation. Interview schedule was the instrument used for data collection

Permission to engaged mothers for the study was obtained from chief nursing officer in charge of each health centre used since there were no ethical committee. Their maximum cooperation assisted the process of data collection. The mother of each infant was approached and was informed the purpose of the study. Consent was obtained. Anonymity of the information was assured. Each mother met at each clinic day was interviewed by the researchers using pre coded interview schedule. The interview was conducted between the hours of 12 noon and $2 \mathrm{pm}$. Data obtained were analysed using descriptive statistics.

\section{Results}

Data in the Table 1 revealed that out of 221 subjects; 118 (53.4\%) were within the age range 25-34years, $65(29.4 \%)$ were within the age range 34-44 years, 20 (11.8\%) were within age range $15-24$ years, while $12(5.4 \%)$ were within the age 45 years and above.

\begin{tabular}{|c|c|c|c|}
\hline \multirow[t]{6}{*}{ A } & Age range & Frequency & Percentage \\
\hline & $15-24$ years & 20 & 11.8 \\
\hline & $2-34$ years & 118 & 53.4 \\
\hline & $35-44$ years & 65 & 29.4 \\
\hline & 45 years and above & 12 & 5.4 \\
\hline & Total & 221 & 100 \\
\hline \multirow[t]{6}{*}{ B } & \multicolumn{3}{|c|}{ Highest Educational Attainment } \\
\hline & No formal education & 11 & 5.0 \\
\hline & Elementary education only & 33 & 14.9 \\
\hline & Secondary education & 134 & 60.6 \\
\hline & Tertiary education & 43 & 19.5 \\
\hline & Total & 221 & 100 \\
\hline \multirow[t]{6}{*}{ c } & \multicolumn{3}{|l|}{ Occupation } \\
\hline & Full time house wife & 26 & 11.8 \\
\hline & Petty trader & 54 & 24.4 \\
\hline & Civil servant & 111 & 12.2 \\
\hline & Student & 27 & 1.4 \\
\hline & Total & 221 & 100 \\
\hline \multirow[t]{8}{*}{ D } & \multicolumn{3}{|l|}{ Number of Children (Parity) } \\
\hline & A child only & 41 & 18.6 \\
\hline & 2 children & 40 & 18.1 \\
\hline & 3 children & 48 & 21.7 \\
\hline & 4 children & 36 & 16.3 \\
\hline & 5 children & 39 & 17.6 \\
\hline & 6 children and above & 15 & 6.8 \\
\hline & Total & 221 & 100 \\
\hline
\end{tabular}

Table 1: Personal characteristics of subjects N=221.

Educationally, 134 (60.6\%) had secondary education, 43 (19.5\%) had tertiary education, 33 (14.9\%) had elementary education only, while only $11(5.0 \%)$ had no formal education. On the basis of occupation, $111(50.2 \%)$ are Civil Servants, $54(24.4 \%)$ are petty traders, $27(12.2 \%)$ are students, $26(11.8 \%)$ are full time house wives, while only $2(9.0 \%)$ are farmers. The parity were that $48(21.7 \%)$ of mothers have three children, $40(18.1 \%)$ have two children, $39(17.6 \%)$ have five children, $41(18.6 \%)$ have only one child, while $15(6.8 \%)$ have six children and above.

Data in Table 2, revealed that out of 221 subjects only 136 (61.5\%) were able to explain weaning as giving the infant adult diet while still breast-feeding. $61(27.6 \%)$ explained it as the introduction of solid food to infant, 38 (17.2\%) explained it as stopping breast-feeding the 
Page 3 of 5

infant, other explanations were giving the infant food without breast milk $17(7.7 \%)$ and 7 (3.2\%) had no idea. Sources of information on weaning practices were varied, up to $138(61.5 \%)$ got: Information from health workers, 53 (24.0\%) got it from parents or mothers and/or sisters-in-laws, 15 (6.8\%) relied on previous experience, others either got information from friends $(4.5 \%, \mathrm{n}=10)$ or from husband $(2.5 \%$, $\mathrm{n}=5)$ or even printed materials by a negligible number $2(0.9 \%, \mathrm{n}=2)$.

\begin{tabular}{|l|l|l|l|}
\hline A & Actual meaning of weaning & $\begin{array}{l}\text { Frequenc } \\
\mathbf{y}\end{array}$ & $\begin{array}{l}\text { Percentag } \\
\mathbf{e}\end{array}$ \\
\hline & $\begin{array}{l}\text { Giving infant adult food while still breast } \\
\text { feeding }\end{array}$ & 90 & 40.7 \\
\hline & $\begin{array}{l}\text { Introduction of solid food to infants } \\
\text { Stopping the infant from breast-feeding }\end{array}$ & 61 & 27.6 \\
\hline & $\begin{array}{l}\text { Giving the infant adult diet without breast- } \\
\text { feeding }\end{array}$ & 17 & 17.6 \\
\hline & Giving the infant artificial milk only & 8.7 \\
\hline & No idea & 7 & 3.6. \\
\hline & Total & 221 & 3.2 \\
\hline B & Sources of Information & 136 & 61.5 \\
\hline & Health workers & 53 & 24.0 \\
\hline & Parents, mothers and/or sister in law & 15 & 6.8 \\
\hline & Previous experience & 10 & 4.5 \\
\hline & Friends & 5 & 2.5 \\
\hline & Husbands & 2 & 0.9 \\
\hline & Printed material & 221 & 100 \\
\hline Total & & \\
\hline
\end{tabular}

Table 2: Level of knowledge of real concept of weaning practice possessed by subjects $\mathrm{N}=221$.

Table 3, revealed that up to $182(82.35 \%)$ of the subjects started weaning their infants from 7 months and above, 17 (7.7\%) started weaning at 5-6 months, $12(5.4 \%)$ started weaning at 3-4 months, while $10(4.5 \%)$ weaned at under 2 months.

Reasons given for weaning the infants; mother being pregnant $(\mathrm{n}=124)$ 55.7, breast milk insufficient $(\mathrm{n}=87) 39.4 \%$, infant rejects the breast milk $(n=79) 35.8 \%$, $(n=12) 5.4 \%$ gave reason that the mother was ill and on medication. The wish of the husband and relations was given as reason by $(n=49) 22.2 \%$, while $(n=26) 13.1 \%$ reasoned that the mother restarted work/schooling, $(n=26) 13.1 \%$ gave reason that the mother did not want to breastfeed.

\begin{tabular}{|l|l|l|l|}
\hline A & Starting age for weaning & $\begin{array}{l}\text { Frequenc } \\
\mathbf{y}\end{array}$ & $\begin{array}{l}\text { Percentag } \\
\mathbf{e}\end{array}$ \\
\hline & Under two months & 10 & 4.5 \\
\hline & At 3-4 months & 12 & 5.4 \\
\hline & At 5-6 months & 17 & 7.7 \\
\hline & At 7-8 months & 62 & 28.1 \\
\hline
\end{tabular}

\begin{tabular}{|l|l|l|l|}
\hline & At 9 months and above & 120 & 54.3 \\
\hline & Total & 221 & 100 \\
\hline B & Reasons for weaning the infant & 124 & 55.7 \\
\hline & Mother became pregnant & 87 & 39.4 \\
\hline & Breast milk insufficient & 79 & 35.8 \\
\hline & Infant rejecting breast milk & 49 & 22.2 \\
\hline & Wish of husband and relations & 26 & 13.1 \\
\hline & Poverty/mothers refusing to breastfeed & 26 & 13.1 \\
\hline & Mother to restart work/schooling & 12 & 5.4 \\
\hline & Mother ill and on medication & & \\
\hline & Total & & \\
\hline
\end{tabular}

Table 3: Showing age weaning started $\mathrm{N}=221$.

\section{Discussion}

This result indicated that sources through which nursing mothers got information included friends $4.5 \%$, parents $20.4 \%$ and mothers and sisters-in-laws $3.6 \%$. This agrees with the findings of Peltos [5]; Onofiok and Nnayelugo [6]; and Sobo, Sokoya, Awonusi and Odufuwa [7] in a study which showed that husbands, mothers and mothers-inlaws have influence on infant's weaning practices. This shows the nature of social interaction people utilize in solving their problems. Relations and significant others share in family affairs including decisions on infant weaning. People do not live in isolation, hence the reason for less stress among Nigerian people.

Previous experience is another source of information indicated by $6.8 \%$ of the respondents. Mothers with more than two children are more likely to have more experience on what to do, but rely entirely on neighbours, friends and mothers. Hence they tend to have nutritional problems of infants like malnutrition, diarrhoea, vomiting, infections etc. Any weaning practice that was favourable is likely to be repeated and encouraged while unfavourable ones are rejected. Through previous experience, people learn the best part of practice to adopt in order to ensure healthy survival of their infants.

It is not surprising that only $9 \%$ of the respondents got their information from printed materials. This is not encouraged and exposed the poor reading potentials of wonder essential health information is now being disseminated through radio and television for wide coverage and utilization. Data further revealed that $5 \%$ of the women had no formal education. At this age of telecommunication it is expected that each individual should have at least primary education to enable him/her communicate effectively with people around.

The major reasons given by more than $70 \%$ of the respondents to justify weaning their infants (Table 3 ) included; mother being pregnant $55.7 \%$, insufficient breast milk flow $39.4 \%$ infant rejected breast milk $35.8 \%$, and mother being ill 33.5. And fear of nipple pains. This agrees with Fawzia and Ezzak [8]; Adele [4]; Ahmed [9]; and Sobo, Sokoya, Awonusi and Odufuwa [7]. Considering the nature of the above reasons one may infer that mothers being pregnant and insufficient breast milk flow may not justify weaning the infant off breast milk. Observation revealed that many mothers are inexperienced regarding techniques and skills of placing the baby on breast for proper suckling 
to occur. In some cases, if the nipple is not properly placed on infant's mouth the tendency is for the infant to bite on the nipple to give mother sores on the nipple. The associated pains and sores make mothers not to breast-feed to avoid further injury to the nipples.

Other reasons given by mothers for weaning include mothers going back to school $1.5 \%$ and some $13.1 \%$ going back to work. This agrees with Noble and Emmet [10]; that mothers who do not believe that they have sufficient milk or that there is something wrong with their milk are more likely to stop breast feeding. Ahmed [9] informed that maternal employment outside home or the need to return to school is a reason for weaning. Ahmed further stated that poor weight gain, unsettled baby including fussiness after feeding, increased feeding frequency, infant. These groups of women are engaged in occupation that are time bound and may not have time to breast feed adequately. This has resulted in mothers hiring inexperienced baby-sitters and nannies with poor knowledge of weaning to care for the infants with the resultant consequences like infections, serious infant mortality and morbidity. Some infants have been damaged because they were mishandled. Some were over drugged and they suffer complications of the effects of over sedation. Through that process, many mothers have suffered the agony and stress of losing their infants.

Time of weaning is another source of concern. Up to $60.5 \%$ of the respondents rightly started weaning their infants from 7 months and above but in same Table 3, 3.7\% mothers and $7.7 \%$ of mothers started weaning their infants at under two months and under 4 months respectively. This is in line with the idea put forward by Onofiok and Nnanyelugo [6] that although majority of women start weaning their infants at age of three months to four months a few begin within the first two months of life. Weaning diet should not be introduced earlier than 6 months of life because such introduction will predispose the infant to hazards such as obesity, malnutrition, flatulence, mental apathy and many others [2], malnutrition can make such an infant not to meet up with the milestone in time, nor make their optimum contributions towards economic and social processes of their community in later life. It is very essential to introduce the diet when the infant is physically and emotionally mature in order to adapt properly to the consistency and taste of weaning diet. More so, at about 7 months and above the normal infant acquires more control over his/her actions and can now manipulate a cup to the lips even if it is held upside down [2]. Between the ages of 8-9 months, imitation is a powerful motivator, so the infant imitates the adult and enjoys using a cup and spoon like others [2,11].

Few respondents, $28.1 \%$ indicated that weaning was started at 5-6 months of age. Interactions with mothers in most rural community primary health care centres and with community health nurses/other health workers show that only few mothers truly start weaning their infants from five months, while majority of women start below 5 months. By five months, have reached some level of developmental maturity and can control their tongue. This agrees with Jensen [12], and Ehiemere [2], that by 5-6 months of life the infant develops a more matured sucking pattern with the tongue, moving back and forth rather than up and down so making spoon feeding easy, because the infant can now draw the lower jaw inwards.

Types of local food substances used for weaning are varied as shown in (Table 3), Majority of the respondents use fermented grains like maize, dawa, guinea corn, millet among others to produce the commonly used weaning food processed in form of gruels called pap (Akamu in local language). Other substances locally produced and used are yam, cocoyam, and potato. These are mainly carbohydrate food which can only provide energy. Protein substances are really missed out [13].

\section{Conclusion}

This study has ex-rayed the weaning practice among breast feeding mothers that attended antenatal, postnatal and child well fare services in Enugu south local government area of Enugu State-Nigeria. The findings reveal that only $61.5 \%$ of the mothers were able to explain the real meaning of weaning; adult diet were introduced as early as the first two months of life; major sources of information were health workers, parents, husband and significant others. Weaning was started at less than two months of age but majority started from seven months and above. Reasons weaning the infant are varied: mother being pregnant, insufficient breast milk, wish of husband, mother and relations were the main reasons provided for starting weaning infants.

\section{Recommendation}

It was recommended that all those entrusted with infant care are challenged to pool their ideas together and create awareness to the inadequacy of the traditional weaning diet as well as produce weaning diet that will improve the process of weaning practice in the entire African region thereby raising the steady health growth of our infants. The use of mass media (radio and television) campaign to illustrate the importance and benefits of appropriate correct weaning practices using our local food stuff is advocated. Seminar/workshops should be organized at local government level to discourse findings of this type of study and similar researches in infant survival strategies.

\section{Implication for Nursing}

Based on the findings of this study, nurses should incorporate the ideals of weaning practices in the health education talks they provide mothers during antenatal, post-natal and child welfare service provided in clinics and health centres located in rural communities.

\section{References}

1. Ndie EC, Ezeruigbo C (2012) Evaluation of infant feeding options and practices by HIV positive mothers attending antiretroviral therapy. Niger J Clin Pract 2: 15-18.

2. Ehiemere IO (1998) Effective weaning practices in the austere times. West Afr J Nurs 9: 102-104.

3. US Department of Health and Human Services, Health Resources and Services Administration and Every Mother Inc (2008) The business case for breastfeeding. Rockville, Maryland.

4. Adele $\mathrm{T}$ (2001) Weaning practices in business between the ages of six to nine months in the inner city of Johannesburg. Afr J Nurs Midwifery 3: 42-45.

5. Pelto GH (1981) Perspective on infant feeding; decision-making and ecology. Food Nutrition Bulletin 3: 16-29.

6. Onofiok NO, Nnanyelugo DO (2005) Weaning foods in West African. Nutritional problem and possible solutions. Department of Home Science and Nutrition; University of Nigeria Nuskka.

7. Sobo RA, Sokoyo GO, Awonusi PA, Odufuwa BA (2008) Knowledge, attitudes and practices of exclusive breastfeeding among rural mothers in Ijebu-Ode Ogun State, Nigeria. West Afr J Med 19: 121-124.

8. Fawzia A, A1-Awadi F, Ezzat KA (1997) Recent trends in infant feeding patterns and weaning practices in Kuwait. East Mediterr Health J 3: 501-510. 
Citation: Ezenduka PO, Ndie EC, Nwankwo CU (2018) Weaning Practices among Breastfeeding Mothers Local Communities of Enugu State Nigeria. Clinics Mother Child Health 15: 293. doi:10.4172/2090-7214.1000293

Page 5 of 5

9. Al-Shoshan AA (2007) Factors affecting mother's choice and decisions related to breastfeeding practices and weaning habits. Pak J Nutr 6: 318-322.

10. Fawzia A, A1-Awadi F, Ezzat KA (1997) Recent trends in infant feeding patterns and weaning practices in Kuwait. East Mediterr Health J 3: 501-510.
11. Whaley LF, Wong D (1983) Nursing care of infants and children. London: The CV Mosby Company.

12. Jensen DM (1981) Maternity care: The nurse and the family. London: CV Mosby Company.

13. Zulkjfli A, Daw WK, Abudul RI (1996) Breastfeeding and weaning practices in rural communities of Kelantan. Mal J Nutr 2: 148-154. 